\title{
Overcoming the Liability of Smallness by Recruiting through Networks in China: A Guanxi-Based Social Capital Perspective
}

\begin{abstract}
We investigate the role of guanxi in Chinese entrepreneurial firms' recruitment practices in attempting to overcome the liability of smallness. Combining insights from the social capital and guanxi literature, we theorize the guanxi-based social capital perspective and use it to analysis 96 in-depth interviews with multiple members (entrepreneurs, senior managers, and factory workers) from 15 die-casting entrepreneurial firms in Guangdong province, China. We find that the use of guanxi in recruitment practice can overcome the liability of smallness because it makes the hiring process more convenient, improves firms' attractiveness to jobseekers, and enhances the person-organizational fit between new hires and firms. We discuss how Chinese entrepreneurs and their senior managers use guanxi strategically to achieve these advantages. On the other hand, our findings suggest that jobseekers can also use guanxi to increase their options, improve their bargaining power, and distract firms' attention away from hiring the most appropriate candidate for the job in order to undermine the effectiveness of Chinese entrepreneurial firms' recruitment procedures. We explore the implications of these findings for academic research and managerial practice.
\end{abstract}

Keywords: Liability of Smallness, Guanxi, Social Capital, Networks, Recruitment, China 


\section{INTRODUCTION}

The liability of smallness suggests that entrepreneurial firms (firms, hereafter) face more challenges in various aspects of their business operations when they lack abundant resources, which limits the level and number of strategic maneuvers in which they can engage (Hannan \& Freeman, 1984). When facing this limitation, previous studies show that Chinese firms often use "guanxi" to access additional resources from their networks to overcome their liability of smallness (Dunfee \& Warren, 2001; Gu, Hung, \& Tse, 2008; Tsui \& Farh, 1997). Guanxi, a combination of two Chinese characters: "guan" meaning "to close" and "xi" meaning "link", represents personal connections among individuals in Chinese society, which have strong implications for interpersonal dynamics (Chen \& Chen, 2004; Gu et al., 2008; Park \& Luo, 2001). There is a substantial body of work showing that guanxi plays a key role in facilitating effective human resource management (HRM, hereafter) functions in Chinese firms in the area of managing the supervisor-subordinate relationship (e.g. Law, Wong, Wang, \& Wang, 2000; Wei, Liu, Chen, \& Wu, 2010), promoting citizenship behavior (e.g. Hui, Law, \& Chen, 1999; Sun, Aryee, \& Law, 2007), HRM planning (e.g. Aycan, 2005; Kim \& Gao, 2010) and others (e.g. Cunningham \& Rowley, 2007, 2008, 2010). In comparison, HRM scholars have done little empirical work on the role of guanxi in the area of recruitment practice (e.g. Cheung \& Gui, 2006; Hsu \& Leat, 2000; Huang, 2008), while recruitment practice, which is the process of attracting, selecting, and appointing individuals who can perform a job effectively (Hsu \& Leat, 2000), is one of the key HRM functions that firm size affects (Barrett, Neeson, \& Billington, 2007; Williamson, 2000).

To address this knowledge gap, we aim to investigate the role of guanxi in Chinese firms' recruitment practice. Specifically, our study focuses on two interrelated research questions. The first research question is: how do Chinese firms use guanxi strategically in 
their recruitment practices? The existing discussions on guanxi and recruitment practice focus primary on demonstrating that guanxi enables Chinese firms to acquire jobseekers through networks (Cunningham \& Rowley, 2007; Hsu \& Leat, 2000; Huang, 2008), while paying less attention to understanding exactly how they use it. As a result, we know little about the processes through which Chinese firms use guanxi strategically in their recruitment practice. The second (and related) research question is: how does the use of guanxi in recruitment practice contribute to overcoming the liability of smallness for Chinese firms? Research that has discussed issues related to the advantages of Chinese firms using guanxi to compete with their larger counterparts in the war for talent is rare and scattered. For example, Hsu and Leat (2000) suggest that the use of guanxi improve recruiters' effectiveness and efficiency with regards to finding and selecting suitable job candidates. Kopnina (2005) describes how the use of guanxi enables employers to access more information about job candidates. As a result, it is difficult to obtain a cohesive picture that delineates the key advantages that Chinese firms can generate by using guanxi strategically in recruitment practice to overcome their liability of smallness.

The goal of this research is to answer these two research questions. We conducted 96 in-depth interviews with multiple members (an entrepreneur, senior managers, and factory workers) from 15 die-casting entrepreneurial firms in Guangdong province, China. We develop and introduce a new theoretical lens - the guanxi-based social capital (GBSC, hereafter) perspective - to analyze our interview data. We find 11 ways in which Chinese firms can use guanxi strategically in their recruitment practice. These approaches enable Chinese firms to overcome their liability of smallness because it makes the hiring process easier, improves firms' attractiveness to jobseekers, and enhances the person-organizational fit between new hires and firms. Furthermore, our results suggest that jobseekers can also use guanxi to increase their options, improve their bargaining power, and distract firms' 
judgement from hiring the most appropriate candidates for a job in order to undermine the effectiveness of Chinese entrepreneurial firms' recruitment procedures.

In developing our arguments, we make several important contributions. First, we show how Chinese firms can use guanxi strategically in their recruitment practice, and the advantages of such a recruitment strategy can help to overcome the liability of smallness. Furthermore, we also point out that, in some situations, jobseekers can use guanxi to undermine the effectiveness of Chinese firms' guanxi-based recruitment strategy. In doing so, we provide a more comprehensive picture of the role of guanxi in recruitment practice (e.g. Cunningham \& Rowley, 2007; Hsu \& Leat, 2000; Huang, 2008). Second, we develop and introduce a new theoretical lens - the GBSC perspective - by integrating insights from the social capital and guanxi literature to interpret the role that guanxi plays in recruitment practice. This approach provides clearer guidance on understanding how the use of guanxi may influence Chinese firms' recruitment practice in different situations. In doing so, we enrich the literature on advocating the connections between social capital and guanxi (e.g. Chen \& Wu, 2011; Gu et al., 2008; Park \& Luo, 2001). Finally, we investigate recruitment practices in the Chinese labor market environment that is facing high economic growth and simultaneously suffering from a lack of well-established institutional and legal systems. Consequently, firms need to rely more on interpersonal ties and trust to practice this key HRM function. In doing so, our study contributes to the HRM and labor market research efforts in emerging or transitional economies (e.g. Cheung \& Gui, 2006; Cunningham \& Rowley, 2007; Hsu \& Leat, 2000; Huang, 2008; Zhu \& Nyland, 2004).

\section{THEORETICAL CONTEXT}

Human capital - the knowledge that employees acquire through investing in schooling, job training, and other experience-enhancing exercises-has long been argued to 
be one of the most critical resources for firms (Cunningham \& Rowley, 2007; Huang, 2008; Leung, Zhang, Wong, \& Foo, 2006). Despite its importance, firms often report challenges in acquiring human capital through recruitment due to their small size (lack of resources). For example, Barber, Wesson, Roberson, and Taylor (1999) indicate that some recruitment practices, such as campus recruitment, are financially demanding and unlikely to be financially viable for smaller firms that hire less regularly. Williamson (2000) suggests that firms often cannot rely on their name (reputation resource) to attract future employees because they have established limited employer legitimacy in the job market during their early stages. To overcome these challenges, firms in Western countries often acquire human capital through networks to offset these limitations. For example, Leung and colleagues (Leung, 2003; Leung et al., 2006) suggest that firms can access information about the availability of potential job candidates and reach them through their relationships with members of various networks. Barrett et al. (2007) found that firms can select appropriate candidates for a job by accessing their information from the network members. Research shows that Chinese firms also adopt such recruitment tactics to overcome their liability of smallness when engaging in recruitment practice (Cunningham \& Rowley, 2008; Hsu \& Leat, 2000; Huang, 2008).

In order for Chinese firms to hire suitable candidates through networks, prior studies point out that guanxi plays an important role in facilitating recruitment practices (Cheung \& Gui, 2006; Cunningham \& Rowley, 2010; Hsu \& Leat, 2000; Kopnina, 2005). Despite its importance, we know very little about exactly how Chinese firms use guanxi in their recruitment practice or how such an approach contributes toward overcoming of the liability of smallness for Chinese firms. Guanxi is commonly conceptualised as personal connections (Su, Mitchell, \& Sirgy, 2007; Yang \& Wang, 2011). Furthermore, it is not a one-dimensional concept but a group of concepts that describe how individuals connect and should behave in 
relationships, such as mianzi (face), jia-ren (family members), renqing (a debt to an acquaintance), guanxi-hu (specially connected individuals), and so on (Chen \& Chen, 2004; Lytras \& de Ordóñez Pablos, 2009; Park \& Luo, 2001; Yang \& Wang, 2011). We apply a social capital lens to categorize and explain these different guanxi concepts to establish the theoretical foundation for our work in this research, based on the reason discussed below.

Scholars have suggested that guanxi is the closest Chinese term for 'social capital' (Chen \& Wu, 2011; Gu et al., 2008; Park \& Luo, 2001). Social capital represents the sum of the actual and potential resources embedded within, available through, and derived from the network of relationships (Inkpen \& Tsang, 2005; Nahapiet \& Ghoshal, 1998). Nahapiet and Ghoshal (1998) suggest that social capital derives from network relationships and the network members have the privilege of accessing it. On the other hand, scholars often use the social capital lens to explain how individuals can draw resources, such as the information, trust and control benefits of interpersonal dynamics, from their guanxi-based social relationships in China (Gold, Guthrie, \& Wank, 2002; Gu et al., 2008). In other words, both guanxi and social capital represent the actual and potential resources that can be drawn from network relationships (Gu et al., 2008). Adopting this perspective, we view guanxi as social capital in the Chinese context. Integrating the insights from Nahapiet and Ghoshal (1998)'s principles of social capital and literature that discusses different concepts of guanxi (e.g. Chen \& Chen, 2004; Gu et al., 2008; Lytras \& de Ordóñez Pablos, 2009; Park \& Luo, 2001), we develop the GBSC perspective to connect different forms of social capital (structural, cognitive, and relational) to parallel guanxi concepts (see Table 1). The perspective provides a clear theoretical foundation for interpreting the role that guanxi plays in recruitment practice.

"Insert Table 1 about here" 
Nahapiet and Ghoshal (1998) describe how the structural dimension of social capital concerns the overall pattern of connections among individuals in networks, which influences access to resources. More specifically, it represents the ways (i.e. direct and indirect) and patterns (i.e. hierarchy and density) through which individuals relate in networks and how these relationships are arranged, which have the potential to affect the amount and diversity of resources that can be accessed by the members of a network (Inkpen \& Tsang, 2005; Jonsson \& Lindbergh, 2013). We argue that guanxi-wang (networks based on guanxi), guanxi-hu (specially connected individuals), jia-ren (a web of family members and close relatives), shou-ren (a web of friends, kin, or clan-based acquaintances and distant relatives), and sheng-ren (a web of relationship with distant acquaintances or strangers) are guanxirelated concepts that connect closely to the structural dimension of social capital because they also represent patterns of relationships among individuals in a network that influence access to resources. Thus, we refer to them as the structural dimension of GBSC. Guanxi-wang refers to the whole network of guanxi through which influence arises (Buckley, Clegg, \& Tan, 2006; McInnes, 1993; Zhu \& Nyland, 2004).

Tung and Worm (2001) suggest that everyone in the same guanxi-wang are obligated to render favors to each other, even if they do not know each other. Guanxi-hu refers to a person, organization, or even government department that occupies a focal point in one's social network (Eng \& Spickett-Jones, 2009; McInnes, 1993). For example, if the relationship between two organizations exists because of an individual, then this individual is the guanxihu. According to Chinese culture, jia-ren is the closest network, and the network members often share similar beliefs (McInnes, 1993; Su \& Littlefield, 2001). Tsui and Farh (1997) indicate that shou-ren usually have a moderate degree of obligation regarding favor exchange. Finally, Sheng-ren has little or no sense of sentiment or obligation (Su \& Littlefield, 2001). These five guanxi-related concepts represent how well firms connect to their networks 
because of guanxi (Chen, 2001; Chen \& Chen, 2004). This echoes the descriptions of the structural dimensions of the social capital of firms. Therefore, we argue that guanxi-related concepts represent the structural dimensions of social capital in the Chinese context- the structural dimension of GBSC.

The cognitive dimension of social capital represents the nature of the connections among the members of networks, which create resources through a shared context, such as values, attitudes, culture, languages, codes, and narratives (Inkpen \& Tsang, 2005; Nahapiet \& Ghoshal, 1998). When individuals believe that the members in their network have a) a mutual understanding of each other's roles in the network, b) similar interpretations of their particular situation, and c) a common system of meaning in their communication, they are more likely to behave as expected when dealing with the other network members. We argue that guanxi-related concepts regarding the development of the cognitive dimension of social capital are tong-xiang (people from the same birthplace), tong-xue (people from the same educational institution), and tong-shi (people from the same workplace) (Chen \& Chen, 2004). The Chinese character for tong means the same, common, shared, or together, which is similar to the cognitive dimension of social capital regarding the common values, beliefs, and systems of meanings shared by the network members. For example, tong-xiang represents people from the same birthplace, and thus they tend to speak the same Chinese dialogue, which improves communication and interactions (Chen, 2001). We argue that guanxi-related concepts such as tong-xiang, tong-xue, and tong-shi represent the cognitive dimension of social capital in the Chinese context, and are hence the cognitive dimension of GBSC.

The relational dimension of social capital refers to assets generated through relationships that individuals develop through a history of interactions (Inkpen \& Tsang, 2005; Jonsson \& Lindbergh, 2013). The prior research recognizes the similarities between the structural and relational dimensions of social capital because both emphasize the 
strengthening of connections (e.g. Jonsson \& Lindbergh, 2013; Moran, 2005), and similarities between the cognitive and relational dimensions of social capital because they reflect attitudes toward the expectations of how others will behave (e.g. Tötterman \& Sten, 2005). However, the relational dimension of social capital represents the assets rooted in networks that mobilize through not only connections or sharing a common understanding and approach to the achievement of outcomes, but also the deeper behavioral and emotional recognition of each other in the relationship. Inkpen and Tsang (2005) and Jonsson and Lindbergh (2013) recognize trust as a central value of the relational dimension of social capital because it represents strong links among the network members, a mutual understanding of appropriate behavior during interactions, and each member's integrity and reliability. Moran (2005) indicates that the relational dimension establishes how much of the potential in a social network can be realized.

We argue that guanxi-related concepts regarding the development of the relational dimension of social capital are renqing (a debt to an acquaintance), mianzi (face), huibao (a reciprocal favor) and xinyong (trustworthiness). Park and Luo (2001) suggest that renqing is an informal social obligation to another party because of a previous exchange of favors, often the first step in a series of exchanges in the future. Mianzi represents an individual actor's social and power status that often reflect his/her social position, material wealth, and collection of favors done in the past, and the anticipatory future favors that may be received (Chen, 2001; Chen \& Chen, 2004). Lee and Dawes (2005) argue that huibao is a reciprocal favor performed by an individual who received a favor in the past. In Chinese culture, people who do not repay favors are consider non-legitimate, and tend to be excluded from social networks (Lee \& Dawes, 2005; Su \& Littlefield, 2001). Yang (1994) describes that xinyong represents integrity, credibility, trustworthiness, reputation and character, as well as a person's credit rating in his/her business circle. Without xinyong, reciprocity cannot begin. 
All four guanxi-related concepts represent behavioral and emotional attitudes that influence individuals' behaviors when they believe that they are in a relationship, similar to the descriptions of the relational dimension of social capital. Buckley et al. (2006) suggest that saving mianzi is critical to maintaining a good relationship and continuing to access resources because it demonstrates the recognition of social standing and position. Chen and Chen (2004) describe how renqing involves an exchange of favors that follows the behavioral rules of interaction, such as a sense of obligation to repay each other. Thus, we argue that guanxibased concepts, such as renqing, mianzi, huibao, and xinyong, represent the relational dimension of social capital in the Chinese context. We refer to them as the relational dimension of guanxi.

Following a series of economic reforms post-1978 and supported primarily by its manufacturing industry, the Chinese economy experienced extensive growth. Due to its low cost of labor and government incentives, China became one of the most important manufacturing bases in the world and host to many entrepreneurial manufacturing firms to deal with the demand from foreign multinationals (Eng \& Spickett-Jones, 2009; Lüthje, 2004). According to recent data, small and medium sized enterprises comprise $99 \%$ of all firms in China, employing nearly $80 \%$ of the country's population (Biz China, 2013). Nevertheless, the mechanisms for recruiting appropriate manufacturing workers through networks are highly complex. Potential candidates are equally capable of using networks to search for the best job offer. We will use GBSC perspective (see Table 1) as the theoretical foundation to study the role of guanxi in Chinese firms' recruitment practices in attempting to overcome the liability of smallness in this context.

\section{RESEARCH METHOD}


Qualitative research appears to be particularly suited to the study of the inherent complexity of recruitment practice from a multi-agent perspective, as it enables the close observation of routine and decision-making (Berg, 2004; Maxwell, 2005). Among various Chinese manufacturing sectors, we focus on the die-casting industry. Die-casting is a process of forcing molten metal under high pressure into reusable steel molds, which enables a manufacturer to produce complex shapes with a high degree of accuracy and repeatability of engineered parts (NADCA, 2013). Although typical Chinese die-casting manufacturers are small and labor-intensive, the entire manufacturing process (e.g. liquid to be injected, the form and shape of a mold, etc.) requires employees with specialized skill sets (Die-Casting, 2013; Folk Group, 2011). Chinese firms in the die-casting industry offer a context in which they need to recruit individuals with appropriate skill sets; not any migrant worker they can find. Without an abundance of resources, the use of guanxi for recruitment is essential for survival.

With their cooperation, we collected 96 in-depth interviews from entrepreneurs, senior managers, and factory workers (engineers) from 15 firms. The average length of each interview was 74 minutes. The interviews were divided into two stages, with separate sets of questions. The first stage involved a discussion of the informant's background in relation to their involvement in recruitment. For the senior managers and factory employees, we also discussed their experiences of being recruited by the firms and previous employers. In the second stage, open-ended questions were discussed in relation to how the firms engaged in recruitment through network contacts, what recruitment consists of in this context, and how potential candidates for a job respond to the firms' recruitment strategies. For senior managers and factory employees, we asked additional questions regarding the experience of getting a job through a network of contacts, and the responses when the firms approached 
them through the networks. We asked the interviewees to describe the reasons and thought processes behind their answers.

All of the informants felt that the interview topic touched on a sensitive aspect of their business and position, so none were willing to be audio-recorded. The majority of informants asked for the interviews to be conducted in a private, informal environment outside their companies (i.e. a private/VIP restaurant), where they felt more comfortable about expressing their views about the interview topics. To compensate, we took the following steps to gather as much information as possible. First, we took detailed notes and asked the informants to confirm key points during the interviews. Second, toward the end of each interview, we spent some time going through the notes with the interviewee to ensure that we had recorded their words correctly. Finally, if we had any queries, we contacted the interviewee by phone or email to request clarification. They appeared happy to assist, on condition that all of our phone calls or e-mails were directed to their personal phone number and e-mail account during nonoffice hours. We triangulated the findings by offering second interview opportunities to enable the informants to comment on points raised by the other informants, and to compare similar discussions in the industry and academic journals about guanxi and recruitment.

We adopted the analysis procedures followed by other grounded theory researchers (Locke, 2001; Strauss \& Corbin, 2008). In the first stage, we transcribed and translated all of the Chinese interview scripts and notes into English. In the second stage, we performed the coding. Following the GBSC perspective (see Table 1), we coded each passage regarding the roles that the different forms of GBSC played in Chinese firms' recruitment practices. Multiple codes can be overlaid onto any given passage when multiple GBSC concepts are found in the text. All of the codes are derived inductively from the interview transcripts and agreed by the authors (Locke, 2001; Strauss \& Corbin, 2008). For example, "Jia-ren" refers to "a web of family members and close relatives" (see Table 1). Using this concept, we assign 
a passage containing a section of text that we have identified as describing recruitment practice related to the use of a web of family members and close relatives to the "Jia-ren" category. In the third stage, we combined all of the categories related to the same form of GBSC to seek connections that would allow us to generate a specific theme to describe how this specific form of GBSC influences Chinese firms' recruitment practices. For example, passages in the "Tong-xiang", "Tong-xue", and "Tong-shi" categories all relate to the cognitive dimension of GBSC (see Table 1). By looking across different passages from these categories, we can generate different themes regarding the influence of the cognitive dimension of GBSC in recruitment practice, such as "individuals, who entrepreneurs and senior managers approved their qualifications for jobs, recommend jobseekers with similar education and training backgrounds" (as one example, see more in Table 2). The fourth stage of the analysis involves organizing the different themes that we identified from the third stage into the overreaching dimensions that eventually underpinned our theory on how Chinese firms attempt to use GBSC to recruit jobseekers through networks to overcome their liability of smallness. Our grounded theorizing approach generates three dimensions here. The first dimension emphasizes how the use of GBSC makes recruitment more convenient (Convenience). The second dimension emphasizes the use of GBSC to improve the attractiveness of firms during recruitment practice (Firms' Attractiveness). Finally, the third dimension describes how the use of GBSC can improve firms' ability to judge the compatibility between the organization and the jobseeker (Person-Organization Fit).

At the end of our data analysis, we took two additional steps to help to ensure the trustworthiness of our data analysis. First, both authors followed the same steps to analyze the data independently. We then assessed and discussed each other's codes until we achieved a strong agreement and there were no discrepancies between our conclusions. Second, we carried out checks across 15 firms in our sample to see whether the themes and dimensions 
from which we developed our findings have been applied in their recruitment practices. We found that most of them were applied. Figure 1 illustrates our final data structure, and shows the presence or absence of our findings applied in the 15 firms' recruitment practices. Given the space limitations, we only present summaries of the interview data and representative quotes concerning each theme.

\section{FINDINGS AND ANALYSIS}

Table 2 illustrates our final data structure, showing the themes and associated activities. Below, we describe our findings in greater detail.

$$
\text { "Insert Table } 2 \text { about here" }
$$

\section{Convenience}

The data suggest that the first challenge of recruitment that Chinese firms face is a lack of financial resources. One senior manager (Firm 1) suggested:

"Big companies have a recruitment process running all the time. [...], for them, to hire a new engineer, it is just a matter of adding a new position name code or even just increasing the quantity code in the [recruitment] system. For us, who are not always looking for people, if we want to use this way to hire people, we need to restart the entire process all over again. It is very costly and time-consuming; our factory simply just does not have that kind of resources."

Entrepreneurs (Firm 4) made similar suggestions:

"If I could afford to spend lots of money on recruitment advertising like those big players in the industry, I would rather use that money to purchase new machines to boost my productivity right now. [...]. Usually, I can find good engineers through my contacts."

The informants suggested that a formal recruitment program appears to be financially demanding from the perspective of Chinese firms. This echoes the finding that a lack of financial resources is the most obvious difference between the recruitment of large and small organizations in Western countries (Barber et al., 1999; Leung et al., 2006). In comparison to larger players in the industry, who have sufficient financial resources to 
support an on-going process, smaller Chinese firms may seek only one or two candidates occasionally. Thus, they view the formal recruitment practice (i.e. job posting and advertising) as a more costly and time-consuming option. We found that Chinese firms prefer to spend even the resources available on purchasing machinery.

To overcome the challenge of a lack of financial resources, the data suggest that Chinese firms use different dimensions of GBSC to make recruitment more convenient. From the structural dimension of the GBSC perspective, we found that Chinese firms could use guanxi to access a pool of potential job candidates from their networks. One entrepreneur (Firm 7) remarked:

"We were trying to find a good engineer to supervise a production line equipped with the new CNC lathes and turning centers that we purchased recently and one of my old friends [shou-ren] quickly helped me to identify a good candidate for this job."

In response to the Chinese labor market situation that engaging in recruitment through formal channels is very time-consuming and may fail to produce qualified candidates (Bian \& Ang, 1997), our findings suggest the important role that guanxi played in recruitment to address this challenge. That is, having a good guanxi with the members of a guanxi network saves a lot of time when recruiting employees because the focal actor can receive help from the members of the network. Furthermore, having and using a wider guanxi network for recruitment also helps Chinese firms to save costs related to recruitment. One senior manager (Firm 12) suggested:

"In my experience, the more people [guanxi-wang] you know, the cheaper and easier it is to find the right people to work for you, because you only need to spend very little or even nothing at all on advertising [job posts]. [...]."

An entrepreneur (Firm 3) provided similar remarks:

"I once successfully hired a mold design engineer quickly through a contact [vice president] at xxx [a regional trade association]. [...] It is much cheaper than running a job advertisement for months with no guarantee of finding the right person". 
Leung (2003)'s work on firms' recruitment practice in Western countries suggests that acquiring information about potential candidates via social networks is an inexpensive way for firms to conduct background checks. Our study on Chinese firms' recruitment practices reveals similar findings: that a wider guanxi network enables Chinese firms to capture more free information from potential candidates for a job. Consequently, they will not spend significant financial resources on searching for the right candidates, which makes the recruitment process less costly.

From the cognitive dimension of the GBSC perspective, our findings also reveal that guanxi plays an important role in helping a company to save on recruitment time and costs. A senior engineer (Firm 4) stated:

"We were close friends back then, at university [tong-xiang]. Our school was very good at teaching knowledge related to die-casting product design. Once I knew that my boss wanted to find a product design engineer, I immediately recommended some of my tong-xiang to him."

An entrepreneur (Firm 13) provided similar remarks:

"Recruiting people by using the contacts that I already have usually costs me less. [...] Ten days ago, I hired someone who is the tong-shi of one of my top engineers. They have known each other for many years."

Evidence from this study suggests that firms can achieve time and cost savings through job referrals. We found that Chinese firms have more confidence in candidates than their contacts from the guanxi networks recommend. This is because the Chinese firms have already approved their contacts' qualifications for a job, and these individuals will recommend someone with a similar education and training background.

From the relational dimension of GBSC perspective, we found that guanxi plays an important role in making recruitment more convenient. One entrepreneur (Firm 5) suggested:

"I trust xxx's [name of an individual's] recommendations [job referrals]. [...] I can just hire those people he suggests to me after a simple phone interview. He [the job referrer] has a good reputation [xinyong] in the industry."

Another entrepreneur (Firm 10) echoed: 
"I sometimes find that the quality of the candidates whom he refers to me is much better than the job applicants who come to me directly [through job advertising]. [...]. This is because he [the referrer] owes me a lot [renqing]. I introduced many clients to him when he started his own factory. He is just repaying the favor.

Trust refers to a willingness to be vulnerable to another party because an individual who trusts another holds a belief in the good intentions, concerns, competencies, capabilities, reliabilities, and perceived openness of the exchange partner (Inkpen \& Tsang, 2005; Nahapiet \& Ghoshal, 1998). The informants suggested that engaging in recruitment through guanxi networks saves both time and money when Chinese firms trust the individuals who refer jobseekers. Due to trust, Chinese firms do not need to devote additional time or money to either verifying the capabilities of prospective employees or exploring other options (e.g. gathering more information about other potential candidates).

From the GBSC perspective, we argue that guanxi plays an important role in allowing Chinese firms to access jobseekers' information through guanxi networks to make recruitment more convenient and offset their lack of financial resources. Simultaneously, we found that jobseekers could also use guanxi to access job-vacancy information to increase their options. One engineer (Firm 3) discussed his experiences during a job search:

"It will be great if you have lots of good friends [i.e. tong-xiang, tong-xue and tongshi] who can help you find a job; it is always good to know more details about the job beforehand. However, even if you do not have this kind of luck, you can still get some necessary information about the job through so-so contacts [sheng-ren]. [...] This allows me to compare different jobs [offers] from different firms before deciding which one is the best one for me".

Similarly, an engineer (Firm 14) provided the following comments:

"I asked my uncle to help me to find a job [...]. He is very influential [mianzi] in this town, people will try to pass information [job vacancies] on to me because of him. This helps me to compare different companies and choose the right one to apply to."

Huang (2008, p. 471) argues that, in the early 2000s, in China, "fast removal of hierarchical institutions and the slow growth of the market institutions have made formal search channels ineffective thus creating growing opportunities for guanxi networks to facilitate the flow of 
information about jobs." Although, since then, the situation concerning the market institutions has improved significantly (e.g., the establishment of many vocational schools, development of a press, etc.), it remains true that guanxi networks play an important role in circulating information about job opportunities in Chinese society. One engineer (Firm 5) added:

"I have gathered a lot of suggestions about the job in this city from many friends. Some of them I know very well, we simply grew up together, some of them are my tong-xue at university or tong-shi at work, and the majority of them I may have only met once or twice, as I got to know them through friends of friends on causal occasions. [...]. Because of the social circle [guanxi-wang] that I am in, I have got lots of job information that I otherwise would not have known if I never got in touch with these friends, [...], even those friends I do not know very well help me a lot by providing me with any job information they have, as a friendly gesture."

When Chinese firms reach jobseekers through social networks, jobseekers may not accept a job offer easily. The findings suggest that jobseekers can also obtain detailed information about a job from their guanxi networks. This allows jobseekers to compare job offers among several firms and choose the best one. This activity has the potential to demand that firms devote more resources to recruitment to reach more jobseekers through guanxi networks before other firms can secure acceptance of job offers.

\section{Firm's Attractiveness}

The second challenge faced by Chinese firms during recruitment is a lack of employer legitimacy. Williamson (2000, p. 28) defines employer legitimacy as "a generalized perception or assumption held by job applicants that an organization is a desirable, proper, or appropriate employer given the system of norms, values, beliefs, and definitions that exist

within an industry." Employer legitimacy concerns jobseekers' perceptions of firm attractiveness. One entrepreneur (Firm 2) suggested:

"Those big factories can offer far more benefits [better catering services, living conditions, training opportunities, etc.] to their employees. Moreover, the big companies with famous names, such as xxx, in this region can also help to raise the 
status of their employees. Especially, when employees go back home during the New Year holiday, they can tell their family and friends in their hometown that they are working for a big name factory. It is a cause of pride for the family."

Surprisingly, we found that the primary reason for Chinese jobseekers' failure to apply for jobs in firms is that they have a special emotional need to be known to work for a well-recognized firm. More specifically, an employee gains much respect from a close circle of friends and family members if he/she works for a well-recognized firm. The employee also experiences a sense of pride on behalf of his/her family, which has unique value in Chinese culture (Cooke, 2004; Dunfee \& Warren, 2001). Chinese firms (which are usually smaller and less recognizable than large firms) face a disadvantage when attempting to attract skilled jobseekers in the job market.

From the structural dimension of the GBSC perspective, we found that Chinese firms attempt to improve firm attractiveness by encouraging the members of the firms' guanxi networks to spread favorable information about the firm to other guanxi networks, whose members have little knowledge about the firm to overcome the lack of firm attractiveness. A senior manager (Firm 14) shared his experiences on this issue:

"If I know someone [jia-ren or shou-ren] close to this person [the jobseeker], I will ask them to speak favorably about our factory. Of course, the more people you know [guanxi-wang], the higher the chance that you will know someone close to your potential employee and make this trick work."

This informant suggests that jobseekers perceive that a Chinese firm has a better reputation when many people give good feedback about it. To increase its good reputation, a Chinese firm needs to establish a wider guanxi network. We also found that this approach is extremely effective if the entrepreneurs and their senior managers can persuade individuals who have a close relationship with jobseekers and good knowledge about the firm to spread favourable about it. 
From the cognitive dimension of the GBSC perspective, our findings reveal that hiring many employees from the same background helps to improve the Chinese firms' attractiveness in their employees' guanxi networks. A senior manager (Firm 8) observed:

"My company has a good reputation in my school. There are altogether five of us from the same school [tong-xue]. The people in my hometown think that our company is great. I usually invite my boss to my hometown to look for other talented engineers."

Another senior manager (Firm 6) made a similar observation:

"I believe we are the best company, with a good reputation for paying engineers a good salary and offering training opportunities. This is simply word-of-mouth, since lots of us who work for this company are from this town [tong-xiang]. Therefore, the people here know us [the company] well and also recognize our status in the diecasting industry."

The informants' suggestions indicate that, when a Chinese firm hires many employees from the same background (i.e. from the same town/village or school), they tend to spread the word about the firm, including details such as the salary, working conditions, etc., to the people they know there. A Chinese firm can take advantage on this notion to enhance its reputation and increase its attractiveness regarding future hiring. At the same time, we also found that a Chinese firm's attractiveness in its guanxi networks improves if the firm recruits respected, high-status individuals from the jobseekers' network. A senior manager (Firm 2) provided the following comments:

"I am working here because some of my tong-xue [top students in class] works here as well. I know one of them got a good offer from a large company in the industry immediately after graduating; however, he chose to work here. There must have been a good reason for him to do so, and therefore it should not be a bad place to work."

This informant indicates that one of the ways in which jobseekers determine the legitimacy of a Chinese firm is to consider its decision to hire individuals whom the jobseekers respect. This accords with Qing (2008)'s suggestion that China is a highly collectivist society in which people define themselves as constituents of several collectives, such as the family, organizations, and other in-groups. If Chinese firms wish to enhance their attractiveness in 
the eyes of potential jobseekers from a particular guanxi network, they can do so by recruiting well-respected individuals from that network.

From the relational dimension of the GBSC perspective, we found that Chinese firms could also use guanxi strategically to improve their attractiveness to jobseekers. One entrepreneur (Firm 11) commented:

"I have a good reputation in this town. People know [xinyong] that I will not take advantage of my employees. I will not ask them to work hard without paying them a good wage. I will not fire them if they get their job done."

A similar response from another entrepreneur (Firm 1) was:

"I reward my employees fairly [huibao] and people tend to spread the word around, no matter good or bad. I have people come to me all the time, because they want to get their kids or relatives a job in my factory."

The informants suggest that a Chinese firm's attractiveness is enhanced when jobseekers have high expectations about what they can get from the firm. For example, Chinese firms can establish a reputation in the jobseekers' guanxi networks to make jobseekers feel rest assured that, if they apply for a job and are willing to work hard, they will be rewarded greatly. This means that entrepreneurs and their senior managers from Chinese firms can improve the firms' attractiveness by making jobseekers aware of the firm's intention and competence to reward their employees.

In general, we found that guanxi plays a critical role in helping Chinese firms to build and promote their reputation through guanxi networks. From the GBSC perspective, we also found that jobseekers could use guanxi to gather more information about firms, which has the potential to undermine firms' efforts to improve attractiveness. One engineer (Firm 1) commented:

"I got this job two years ago. [...]. I learnt about the job through chatting with my very close tong-xue at university during our annual alumni reunion. He told me a lot of details (i.e. the company's background, working environment) about this job and promised to help me to get it if I really wanted it.

Another engineer (Firm 13) made similar remarks: 
"I asked everyone I knew [guanxi-wang] who had heard about this company, including the person who introduced me to my boss. Apart from the salary and benefits package, I wanted to know whether the people here [my boss and colleagues] are nice to work with and whether they will take advantage of others or not. Their answers helped me to make the final decision."

The findings suggest that jobseekers believe that the members of their guanxi network can provide them with more information about jobs. This suggests that, even though the Chinese firms can use guanxi to increase their attractiveness by asking the members of their guanxi networks to spread favorable words about the firms, jobseekers can also use them to find out exactly what the firms are about. When jobseekers use guanxi to discover more information about firms, this subsequently improves their bargaining power against these firms. One engineer (Firm 8) suggested:

"My friend [shou-ren] told me how much my boss is usually willing to pay for an engineer like me and how much he paid the individual who did the job previously [...]. I can use this information when discussing my salary with my future boss."

Another engineer (Firm 15) offered other perspective:

"My uncle [jia-ren] introduced to me to this job when I graduated from a technical institution without any practical experience of die-casting. He is the second in command at this company, in charge of the engineering and production department. My boss asked him to tell others how good the company is. [...] I am just taking advantage of this situation. [...] I also think that, because of this, my boss paid me more than the other new engineers to show respect [mianzi] to my uncle and repay some renqing he owed. Of course, I believe that my uncle also has something to do with this.

Seidel, Polzer, and Stewart (2000, p. 16) point out that "the two principle advantages involve the transmittal of inside information to the applicant by the employed friend and the influence the friend may wield within the company to help the applicants to get favorable terms." Similar to comments made by Seidel et al. (2000), we found that jobseekers enjoy two advantages in this situation: an informational and a relational advantage. An informational advantage arises when the members of a guanxi network pass sensitive information about a firm to the jobseekers who request it. Jobseekers can leverage this information to improve their bargaining power when negotiating with a company about job 
offers. A relational advantage arises through having close relationships with the insiders of a firm who can help jobseekers in multiple ways, which subsequently improves the jobseekers' bargaining power to get good job offers. This improvement increases the jobseekers' bargaining power, undermining the Chinese firms' efforts to improve their attractiveness.

\section{Person-organization Fit}

The final challenge that Chinese firms face is the lack of a well-established recruitment system. Barber et al. (1999, p. 844) suggest that large firms are more likely "to have dedicated human resources professionals," "follow a regular, and often extended, recruitment system," and "to be flexible with regard to start dates for new employees because they have more resources to draw from in temporarily covering vacant positions or in carrying extra personnel in the event that some one wishes to start work earlier than anticipated". As a result, this gives the large organizations a better opportunity to find suitable employees for their business operations. A senior manager (Firm 5) provided the following observations to reflect the above discussion:

"We cannot compete with the big factories on this issue [recruitment]. Think about it, they create a [human resources] department just for this purpose. For us, my boss is "THE" human resources department; he is the one and only person responsible for the recruitment practices. [...]."

A senior manager (Firm 8) offered:

"A large factory finds it easier to get the best employees, because they can afford to hire anyone who knocks on their door as a trainee, slowly sort out the good ones from the bad ones, and finally offer the long term contact to the one whom they think is the best. As a small factory, we cannot do this."

Kristof (1996) suggests that the person-organization fit concerns compatibility between a person and an organization when at least one entity provides what the other needs and they share similar fundamental characteristics. Leung and colleagues indicate that the fit between the organization and the employees has a positive effect on employee attitudes, such as job 
satisfaction and commitment (Leung, 2003; Leung et al., 2006). To find "fit" employees, the informants point out that the large organizations enjoy many advantages due to their wellestablished recruitment system, detailed descriptions of the job requirements and clearly defined roles for particular jobs. This allows the large organizations gradually to filter out the "fit" employees from the "non-fit" ones. In contrast, the smaller Chinese firms do not enjoy this kind of luxury. In the smaller Chinese firms, the job descriptions are very vague and lack clear definition, since individual employees are required to take on many different tasks. The same phenomena can also be observed in Western firms; Heneman and Berkley (1999, p. 53) describe how small organizations have a "high number of single incumbent and employees typically perform multiple roles with unclear boundaries regarding the respective job role responsibilities." In order to compete with the larger firms, smaller Chinese firms need to hire "fit" employees from the start.

From the structural dimension of the GBSC perspective, we found that Chinese firms could use guanxi to improve the person-organization fit and overcome this challenge. More specifically, our findings suggest that Chinese firms use guanxi to obtain detailed information about potential job candidates. One senior manager (Firm 10) suggested:

"If you know a lot of people [guanxi-wang or guanxi-hu], they can help you to acquire useful information about potential people for the job. For example, we were looking to hire an engineer for a new process upgrade and already had an idea about who this person is. However, after making a few phone calls to the people who know this person well, we eventually decided not to hire him. I will not tell you the reason why, but I definitely would not have known about it in advance if I had not engaged in a well-connected guanxi-wang with the people close to this person."

This response suggests that guanxi networks allow Chinese firms to acquire more information about potential candidates. Such practices help firms to determine the person-organization fit of potential employees. The informant indicates that a well-connected guanxi-wang allowed him to gather more information about the person he wanted to hire. A well-connected guanxi- 
wang allows firms to gather information from multiple sources to improve the reliability of this information.

From the cognitive dimension of the GBSC perspective, we found that Chinese firms could use guanxi to improve the person-organization fit. The informants suggested that individuals with similar backgrounds and histories tend to recognize each other's career ambitions and capabilities better. Chinese firms can use this information to screen employees who are more suitable for the job and the firm. A senior manager (Firm 7) made the following suggestions:

"I have known my friend for more than 30 years. We grew up together and know each other well [tong-xiang]. At university [tong-xue], he always came top of the mechanical engineering class. One day, my boss came to me and asked me to recommend someone to him for a new project; I immediately knew whom I should contact."

One entrepreneur (Firm 9) added:

"They [members of the guanxi network] will usually recommend someone whom they knew very well and who is capable of doing this kind of work [i.e. tong-xiang, tongxue or tong-shi]. [...]"

These informants suggest that individuals with similar backgrounds and histories to the jobseekers provide detailed, sensitive information about them (e.g., their personality, capabilities, etc.). Therefore, firms can gain a better understanding about jobseekers and determine their fitness for the company. A special feature of the recent Chinese industrialization has been the extensive use of migrant labor. The cause of migrant workers is the hukou system, which allows people to live, work, and study in a city, but makes it difficult if they wish to live in another city (Zhang, 2001). Fueled by economic reform and the improved efficiency of agricultural production, the rural labor force finds itself no longer needed for agricultural work, and so must seek work elsewhere (Hare \& Zhao, 2000; Zhao, 2003). Since the late 1980s, it has become increasingly difficult to reinforce this policy because employers enjoy greater flexibility in hiring people (Liang, Chen, \& Gu, 2002; 
Zhang, 2004). Internal migration has fueled an increasing movement of workers toward the industrial regions. Most of these migrant laborers bond to form small social cycles (guanxi networks) while they are away from home (Zhang, 2001; Zhao, 2003). Without a proper system for documenting and verifying the candidates' skill-sets (as in a mature labor market), the social networks appear to be one of few reliable ways to search for and access qualified skilled workers (Cooke, 2004; Cunningham \& Rowley, 2008; Zhu \& Nyland, 2004). Through accessing these networks, Chinese firms can take advantage of information concerning potential candidates for an opening (Cooke, 2004; Zhu \& Nyland, 2004).

From the relational dimension of the GBSC perspective, we found that Chinese firms can use guanxi strategically to enhance the person-organization fit. One entrepreneur (Firm 6) claimed:

"My friends know my personality very well. Therefore, they will not introduce a candidate to me whom they feel will not fit into my company, because this might damage our friendship. On the other hand, I will give my friend a big red packet [huibao] in return if they find me a good engineer."

To improve the person-organization fit during a hiring decision, Chinese firms build close guanxi relationships with individuals who can provide information about suitable candidates for a job and the firm through the mutual reinforcement of favors. This echoes Bian and Ang (1997, p. 989)'s suggestion that individuals who recommend candidates to firms "wish to protect their own reputation, they do not recommend just anyone but only those who they believe will be good workers for the company." Here, guanxi networks act as a source of private information that neither appears on the candidates' job application nor emerges during the interview process. This is in line with the finding of Leung (2003): that firms in Western countries use social ties to obtain more information about potential candidates and ensure the fitness between the company and its employees. However, unlike the situation that firms in the Western countries have encountered, the use of guanxi is not entirely "free." In other words, the trust that emerges through using guanxi between the Chinese firms and individuals 
who provide information about suitable candidates arises from the anticipation of corresponding future rewards. For example, the quotations above also suggest that, once individuals provide potential candidates' information to firms, Chinese entrepreneurs or senior managers immediately offer something in return for the favor. Prior studies suggest that such movements enable Chinese firms to maintain trust with individuals who can provide information about suitable job candidates, so that they can use guanxi again in their future recruitment practice (Cheung \& Gui, 2006; Hsu \& Leat, 2000; Huang, 2008).

In general, we found that guanxi plays a critical role in enhancing Chinese firms' ability to screen suitable jobseekers for a job by acquiring information from guanxi networks and achieving a greater person-organizational fit in recruitment practice. From the GBSC perspective, we also found that such movements become limited when jobseekers also use guanxi to influence firms' hiring decisions. For example, we found that jobseekers sometimes obtain job-vacancy information before the information appears on the job market. One engineer (Firm 9) suggested:

"If we have a new engineer vacancy, I will first notify my tong-xiang or close friends [shou-ren] and encourage them to apply for it. [...]. I will do my best to help them to get it if they really like the job because it's nice to have someone you know in the same workplace; you feel safe. It's even better if they are your jia-ren [family members], because it can help to boost the family earnings and improve our living standard."

An engineer (Firm 11) from another firm made a similar remark:

"You probably never find job information in the papers. [...], usually, good jobs are already reserved for people who use renqing or someone with higher social status [mianzi] to help to persuade company insiders to get the information faster or have the ability to influence the decision-making process."

Bian (1997) suggests that strong connections with job-assigning authorities or the individuals who can influence these authorities also have a large impact on job searches because, even when jobseekers have information, they typically cannot apply for jobs. The findings suggest that the members of a guanxi network can pass on key information about a job-especially 
desirable positions - to jobseekers and help them to obtain information about job vacancies before they are released to the public. This is in line with Cheung and Gui (2006)'s suggestion that, in China, jobseekers who have greater "guanxi" with individuals who can influence job-assigning authorities have greater access to more rewarding jobs. This means that highly desirable jobs are often filled before they are advertised to the public. From the Chinese firms' perspective, such practice limits the number of candidates available for them to evaluate and choose to hire. This implies that firms may be unable to select the "best" candidates for a job due to the interference of influential guanxi network members. One engineer (Firm 7) described his experience as follows:

"I like to work with someone from the same town [tong-xiang]. It is easier to communicate with each other because we can speak the same dialect [language]. Therefore, we feel closer to each other and it is easier to cooperate over work. [...]. When I was looking for a place to work, I ask my relative to recommend me to the factory where many people from my home town work."

We found that, when people bond closely in a guanxi relationship, they are more willing to help each other to search for and provide information about available jobs. The informants indicated that this familiarity allows them to cooperate better over job-related tasks due to the improved communication. The quotation above also suggests that this may be because people from the same place speak the same Chinese dialect, which makes them feel closer and more willing to cooperate in the workplace. This motivates members of the same guanxi network to help each other with job searches. Given that guanxi, as an inward-looking system, is relatively slow to accept new members because it takes time to form strong, particularistic ties, Fukuyama (1995) describes this as a low-trust society in which people only trust others who are in their close social circle. Applied to job searches, it is more likely for members of the same guanxi network to recommend individuals with whom they have a close guanxi relationship but are not the most appropriate or qualified candidates for the job. Combined, 
the firms' judgement about hiring the most appropriate candidate for a job may be distracted when jobseekers also use guanxi for job searches.

\section{DISCUSSION AND CONCLUSION}

The objective of this study was to investigate the role of guanxi in Chinese firms' recruitment practice in attempting to overcome the liability of smallness. We analysis 96 indepth interviews with multiple members (an entrepreneur, senior managers, and factory workers) from 15 die-casting Chinese firms using the GBSC perspective as our theoretical lens. The findings of our study enrich the relevant literature in several ways. First, our findings provide a more comprehensive picture of the Chinese firms' recruitment practice and the important role that guanxi plays in such practice. More specifically, we found that Chinese firms face three major challenges during recruitment because of their organization's size (liability of smallness), including a lack of financial resources, employer legitimacy, and a well-established recruitment system. Through the theoretical lens of GBSC, we identify 11 ways in which Chinese firms can use guanxi strategically to improve their recruitment practice (see Table 2). Together, these approaches help Chinese firms to make the recruitment procedures more convenient, improve firms' attractiveness to jobseekers, and enhance the person-organization fit between new hires and the firms, which ultimately overcomes their liability of smallness during recruitment. On the other hand, we also found that guanxi not only plays a positive role in improving Chinese firms' recruitment practice, but also a negative role in undermining the effectiveness of the firms' recruitment procedures. More specifically, we found that jobseekers also use guanxi strategically to increase their options, improve their bargaining power, and distract firms from hiring the most appropriate candidates for a job. In general, our findings imply that guanxi is a double-edged sword when used during recruitment practice in China. Our work extends our current understanding about 
the role of guanxi in recruitment practice for Chinese firms (e.g. Cheung \& Gui, 2006; Hsu \& Leat, 2000; Huang, 2008), as well as the small firms' recruitment strategy literature in general by providing a more comprehensive picture about Chinese firms' recruitment practice (e.g. Leung, 2003; Leung et al., 2006; Williamson, 2000).

Second, we introduce the GBSC perspective. The prior literature on the use of networks by Chinese firms has approached this from two perspectives: (1) applying social capital theory as a theoretical lens to understand interpersonal dynamics (Fukuyama, 1995; Wu \& Leung, 2005), and (2) drawing insights from different concepts of guanxi to explain how an individual behaves in the network environment (Chen \& Chen, 2004; Huang, 2008; Su et al., 2007). Our study reconciles these two approaches by connecting different forms of social capital and parallel guanxi concepts to develop the GBSC perspective as a new theoretical lens to analyze recruitment practice in China. Our findings demonstrate that this analytical approach is useful in drawing a stronger distinction regarding the effects of the different dimensions of GBSC on Chinese firms' recruitment practice. In doing so, we help to explain the connections between social capital and guanxi beyond the current research, that has already established a strong link between these two relevant concepts (e.g. Chen \& Wu, 2011; Gu et al., 2008; Park \& Luo, 2001). Future researches who wish to perform heavy, text-based data analysis, such as content analysis or meta-analysis, may also use this approach to study the impact of social capital on Chinese businesses.

Finally, we have gone well beyond the previous work on HRM practice in the Chinese labor market environment, which faces high economic growth and simultaneously suffers from a lack of well-established institutional and legal systems, similar to other labor market environments in emerging or transitional economies (Bian, 1997; Cooke, 2004; Zhao, 2003). Our current findings not only highlight the importance of Chinese firms' capabilities to use guanxi to bridge information asymmetries in the Chinese labor market, but also 
provide a comprehensive picture of the activities taking place between employers and employees, with both parties using guanxi strategically to maximize the advantages during the recruitment process. Our work, therefore, provides fresh insights into how firms can organize their HRM practices to overcome their liability of smallness in this kind of labor market environment and contribute to the relevant research in this subject area (e.g. Cheung \& Gui, 2006; Cunningham \& Rowley, 2007; Hsu \& Leat, 2000; Huang, 2008; Zhu \& Nyland, 2004).

This study also has implications for entrepreneurs and senior managers during recruitment. We identify some approaches (see the Table 1) through which Chinese firms can use guanxi to offset the lack of resources during recruitment. Entrepreneurs and senior managers who wish to recruit appropriate job candidates can implement these approaches to take advantage of guanxi. Simultaneously, entrepreneurs and senior managers should also be aware that jobseekers can also use guanxi to find appropriate jobs though networks. Knowing what jobseekers can do to undermine the recruitment procedures, firms can plan to deal with potential negative consequences.

\section{Limitations and Future Research Opportunities}

The generalizability of the findings is a limitation of this study, which focuses on a single sub-sector of a single industry. Although this focus allowed us to explore the variety of roles that guanxi plays during recruitment, it also hindered our ability to draw broader conclusions across the field. The conclusions of this study arise from an analysis of 96 indepth interviews with multiple members (an entrepreneur, senior managers, and factory workers) from 15 die-casting firms, though drawn from a larger, focused population. The additional studies conducted using various sub-sectors of the manufacturing industry or sectors of several industries could help to establish generalizability. Future researchers should 
adopt the same research method and expand it to other industries, such as the financial and retail industries. This expansion to other industries would allow researchers to compare the interviewees' responses and identify the differences among disparate industry practices.

A second limitation concerns the data quality. All of the informants wished to remain anonymous. We took detailed notes during the interviews, but the participants did not wish us to record them verbatim. We tried diligently to write everything down but, inevitably, we missed some messages that might have contributed to our findings. If future researchers have better access to subjects, they may be able to acquire in-depth information (i.e. internal documents, e-mails, etc.) or be granted comprehensive permission (i.e. to audio record interviews, make field study observations, etc.). We acknowledge that, if researchers are too close to the research subjects, they may encounter problems in establishing objectivity, and the permission to audio record may diminish the informants' willingness to share opinions and knowledge about a sensitive subject.

The choice of a qualitative research method constitutes another research limitation. In this research, we adopt this type of method to explore the use of guanxi in recruitment practice by Chinese firms. We show 11 different ways to use guanxi in recruitment practice for different firms (see Table 2). This allows us to interpret how widespread the use of guanxi is in improving recruitment practice across our sample. Nevertheless, the qualitative research approach might help us to build theory about the use of guanxi, but does not enable us objectively to assess the frequency of use or to measure the strength of each way of using guanxi to affect Chinese firms' recruitment practice. For example, we identify that Chinese firms use guanxi to "access a pool of potential candidates for a job through guanxi network", but we cannot determine how effective this approach is and how frequently firms apply it to recruit candidates. Similarly, we show that jobseekers can also use guanxi to undermine the effectiveness of firms' guanxi-based recruitment practice in this research. However, the 
qualitative research approach limits our assessment of the effectiveness of jobseekers' guanxi-based strategy. Future research should use quantitative surveys to test the effectiveness of using guanxi for both firms and jobseekers during recruitment practice.

In addition to the discussion of the limitations and ways to overcome these in future research design, we also offer several specific suggestions for future work. Our research has documented how Chinese firms use guanxi in their recruitment practice. These findings stimulate additional research questions regarding the relationship between the use of guanxi by employers/employees and recruitment practice in large Chinese firms (with more formal procedures), given that guanxi represents the personal connections among individuals in Chinese society and its functions have strong implications for interpersonal and interorganizational dynamics (Dunfee \& Warren, 2001; Gu et al., 2008; Su et al., 2007). Future research might want to address this question by studying whether or to what extent guanxi influences the recruitment practice in large Chinese firms. Furthermore, even though our interviews cover both the experience of being recruited and the experience of recruiting others, however our interview questions are still mainly designed to answer our research questions regarding how Chinese firms attempt to use guanxi to recruit jobseekers through networks to overcome the limitations of smallness during recruitment practice. Thus, the themes and dimensions from which we developed our findings are from the recruiters' perspectives. Despite this, we identified several practices related to using guanxi that the jobseekers adopted to undermine the recruiters' efforts and discussed in our findings as a "double-edge sword," from analyzing the jobseekers' experience of being recruited. Researchers in the future might want to design a full-scale study on the use of guanxi from the jobseekers' perspective and compare their findings with our current findings to establish a comprehensive view on the use of guanxi in recruitment practice for Chinese firms. 
What's more, our findings show that guanxi plays a critical role in facilitating recruitment, improving firm attractiveness to jobseekers, and enhancing the personorganization fit between new hires and firms. However, these issues mainly relate to the economic and labor context of recruitment practices. This raises some questions of interest regarding the legal aspects of recruitment practices: how do Chinese firms address the transparency issue when hiring employees using the guanxi relationship? Can firms ensure equality of opportunity when entrepreneurs and their senior managers use guanxi strategically during recruitment practice? However, our data do not provide any further explanation regarding how Chinese firms deal with these issues. Future work should design interview questions in a qualitative study to address these legal issues directly. Despite these limitations, this study enhances our current understanding of the use of guanxi by Chinese firms during their recruitment practice. 
Reference 
Aycan, Z. (2005). The interplay between cultural and institutional/structural contingencies in human resource management practices. International Journal of Human Resource Management, 16(7), 1083-1119.

Barber, A.E., Wesson, M.J., Roberson, Q.M., \& Taylor, M.S. (1999). A tale of two job markets: Organizational size and its effects on hiring practices and job search behavior. Personnel Psychology, 52(4), 841-868.

Barrett, R., Neeson, R., \& Billington, L. (2007). Finding the "right staff" in small firms. Education + Training, 49(9), 686-697.

Berg, B.L. (2004). Qualitative research methods for the social sciences. Boston: Pearson.

Bian, Y. (1997). Bringing strong ties back in: Indirect ties, network bridges, and job searches in China. American Sociological Review, 62(3), 366-385.

Bian, Y., \& Ang, S. (1997). Guanxi networks and job mobility in China and Singapore. Social Forces, 75(3), 981-1005.

Biz China, (2013). SMEs become major force in promoting innovation in China. Retrieved from http://news.xinhuanet.com/english/china/2012-06/22/c_131670359.htm

Buckley, P.J., Clegg, J., \& Tan, H. (2006). Cultural awareness in knowledge transfer to China: The role of guanxi and mianzi. Journal of World Business, 41(3), 275-288.

Chen, M.J. (2001). Inside Chinese business: A guide for managers worldwide. Boston, Mass.: Harvard Business Press.

Chen, X., \& Wu, J. (2011). Do different guanxi types affect capability building differently? A contingency view. Industrial Marketing Management, 40(4), 581-592.

Chen, X.P., \& Chen, C.C. (2004). On the intricacies of the Chinese guanxi: A process model of guanxi development. Asia Pacific Journal of Management, 21(3), 305-324.

Cheung, C.-k., \& Gui, Y. (2006). Job referral in China: The advantages of strong ties. Human Relations, 59(6), 847-872.

Cooke, F.L. (2004). HRM, work and employment in China. London: Routledge.

Cunningham, L.X., \& Rowley, C. (2007). Human resource management in Chinese small and medium enterprises: A review and research agenda. Personnel Review, 36(3), 415439.

Cunningham, L.X., \& Rowley, C. (2008). The development of Chinese small and medium enterprises and human resource management: A review. Asia Pacific Journal of Human Resources, 46(3), 353-379.

Cunningham, L.X., \& Rowley, C. (2010). Small and medium-sized enterprises in China: a literature review, human resource management and suggestions for further research. Asia Pacific Business Review, 16(3), 319-337.

Die-Casting, (2013). Die Casting. Retrieved from http://automobile.dmc.co.kr/english/product/index.php?part=etc\&path=Die_Casting

Dunfee, T.W., \& Warren, D.E. (2001). Is guanxi ethical? A normative analysis of doing business in China. Journal of Business Ethics, 32(3), 191-204.

Eng, T.-Y., \& Spickett-Jones, J.G. (2009). An investigation of marketing capabilities and upgrading performance of manufacturers in mainland China and Hong Kong. Journal of World Business, 44(4), 463-475.

Folk Group, (2011). State of the metal casting industry by country. Retrieved from http://www.folkgroup.com/linked/stateofhteindustrybycountry.pdf

Fukuyama, F. (1995). Social capital and the global economy. Foreign Affair, 74(5), 89-103.

Gold, T., Guthrie, D., \& Wank, D.L. (2002). Social connections in China: Institutions, culture, and the changing nature of guanxi. Cambridge, U.K.: Cambridge University Press.

Gu, F.F., Hung, K., \& Tse, D.K. (2008). When does guanxi matter? Issues of capitalization and its dark sides. Journal of Marketing, 72(4), 12-28. 
Hannan, M.T., \& Freeman, J. (1984). Structural inertia and organizational change. American Sociological Review, 49(2), 149-164.

Hare, D., \& Zhao, S. (2000). Labor migration as a rural development strategy: A view from the migration origin. In West, L.A. \& Zhao, Y. (Eds.), Rural Labor Flows in China (pp. 148-178). Berkeley, CA.: University of California Press.

Heneman, H.G., \& Berkley, R.A. (1999). Applicant attraction practices and outcomes among small businesses. Journal of Small Business Management, 37(1), 53-74.

Hsu, Y.-R., \& Leat, M. (2000). A study of HRM and recruitment and selection policies and practices in Taiwan. International Journal of Human Resource Management, 11(2), 413-435.

Huang, X. (2008). Guanxi networks and job searches in China's emerging labour market: A qualitative investigation. Work, Employment \& Society, 22(3), 467-484.

Hui, C., Law, K.S., \& Chen, Z.X. (1999). A structural equation model of the effects of negative affectivity, leader-member exchange, and perceived job mobility on in-role and extra-role performance: A Chinese case. Organizational Behavior and Human Decision Processes, 77(1), 3-21.

Inkpen, A.C., \& Tsang, E.W.K. (2005). Social capital, networks, and knowledge transfer. Academy of Management Review, 30(1), 146-165.

Jonsson, S., \& Lindbergh, J. (2013). The development of social capital and financing of entrepreneurial firms: From financial bootstrapping to bank funding. Entrepreneurship Theory and Practice, 37(4), 661-686.

Kim, Y., \& Gao, F.Y. (2010). An empirical study of human resource management practices in family firms in China. International Journal of Human Resource Management, 21(12), 2095-2119.

Kopnina, H. (2005). Family matters? Recruitment methods and cultural boundaries in Singapore Chinese small and medium enterprises. Asia Pacific Business Review, 11(4), 483-499.

Kristof, A.L. (1996). Person-organization fit: An integrative review of its conceptualizations, measurement, and implications. Personnel Psychology, 49(1), 1-49.

Law, K.S., Wong, C.-S., Wang, D., \& Wang, L. (2000). Effect of supervisor-subordinate guanxi on supervisory decisions in China: An empirical investigation. International Journal of Human Resource Management, 11(4), 751-765.

Lee, D.Y., \& Dawes, P.L. (2005). Guanxi, trust, and long-term orientation in Chinese business markets. Journal of International Marketing, 13(2), 28-56.

Leung, A. (2003). Different ties for different needs: Recruitment practices of entrepreneurial firms at different developmental phases. Human Resource Management, 42(4), 303320.

Leung, A., Zhang, J., Wong, P.K., \& Foo, M.D. (2006). The use of networks in human resource acquisition for entrepreneurial firms: Multiple "fit" considerations. Journal of Business Venturing, 21(5), 664-686.

Liang, Z., Chen, Y.P., \& Gu, Y. (2002). Rural industrialisation and internal migration in China. Urban Studies, 39(12), 2175-2187.

Locke, K.D. (2001). Grounded theory in management research. Thousand Oaks, CA: SAGE Publications Ltd.

Lüthje, B. (2004). Global production networks and industrial upgrading in China: the case of electronics contract manufacturing. Honolulu, HI: East-West Center.

Lytras, M.D., \& de Ordóñez Pablos, P. (2009). Guanxi and information technology companies in China: Understanding social connections structures. In Lytras, M.D. \& de Ordóñez Pablos, P. (Eds.), The China Information Technology Handbook (pp. 1-9). New York: Springer. 
Maxwell, J.A. (2005). Qualitative research design: An interactive approach. Thousand Oaks, CA.: Sage Publications, Inc.

McInnes, P. (1993). Guanxi or contract: a way to understand and predict conflict between Chinese and Western senior managers in China-based joint ventures, Research on Multinational Business, Management and Internationalisation of Chinese Enterprises (pp. 345-351). Nanjing University, Nanjing.

Moran, P. (2005). Structural vs. relational embeddedness: Social capital and managerial performance. Strategic Management Journal, 26(12), 1129-1151.

NADCA, (2013). About Die Casting. Retrieved from http://www.diecasting.org/faq/

Nahapiet, J., \& Ghoshal, S. (1998). Social capital, intellectual capital, and the organizational advantage. Academy of Management Review, 23(2), 242-266.

Park, S.H., \& Luo, Y. (2001). Guanxi and organizational dynamics: Organizational networking in Chinese firms. Strategic Management Journal, 22(5), 455-477.

Qing, X. (2008). The culture relativity in the knowledge flow: An integrative framework in the Chinese context. Chinese Management Studies, 2(2), 109-121.

Seidel, M.-D.L., Polzer, J.T., \& Stewart, K.J. (2000). Friends in high places: The effects of social networks on discrimination in salary negotiations. Administrative Science Quarterly, 45(1), 1-24.

Strauss, A.L., \& Corbin, J.M. (2008). Basics of qualitative research: Techniques and procedures for developing grounded theory. Newbury Park, CA.: Sage Publications.

Su, C., \& Littlefield, J.E. (2001). Entering guanxi: a business ethical dilemma in mainland China? Journal of Business Ethics, 33(3), 199-210.

Su, C., Mitchell, R.K., \& Sirgy, M.J. (2007). Enabling guanxi management in China: A hierarchical stakeholder model of effective guanxi. Journal of Business Ethics, 71(3), 301-319.

Sun, L.-Y., Aryee, S., \& Law, K.S. (2007). High-performance human resource practices, citizenship behavior, and organizational performance: A relational perspective. Academy of Management Journal, 50(3), 558-577.

Tötterman, H., \& Sten, J. (2005). Start-ups business incubation and social capital. International Small Business Journal, 23(5), 487-511.

Tsui, A.S., \& Farh, J.L. (1997). Where guanxi matters relational demography and guanxi in the Chinese context. Work and Occupations, 24(1), 56-79.

Tung, R.L., \& Worm, V. (2001). Network capitalism: The role of human resources in penetrating the China market. International Journal of Human Resource Management, 12(4), 517-534.

Wei, L.-Q., Liu, J., Chen, Y.-Y., \& Wu, L.-Z. (2010). Political skill, supervisor-subordinate guanxi and career prospects in Chinese firms. Journal of Management Studies, 47(3), 437-454.

Williamson, I.O. (2000). Employer legitimacy and recruitment success in small businesses. Entrepreneurship Theory and Practice, 25(1), 27-42.

Wu, W.-p., \& Leung, A. (2005). Does a micro-macro link exist between managerial value of reciprocity, social capital and firm performance? The case of SMEs in China. Asia Pacific Journal of Management, 22(4), 445-463.

Yang, M.M. (1994). Gifts, favors, and banquets: The art of social relationships in China. Ithaca, N.Y.: Cornell University Press.

Yang, Z., \& Wang, C.L. (2011). Guanxi as a governance mechanism in business markets: Its characteristics, relevant theories, and future research directions. Industrial Marketing Management, 40(4), 492-495.

Zhang, J. (2004). Government and Market in China: A Local Perspective. Hauppauge, NY.: Nova Science Pub Incorporated. 
Zhang, L. (2001). Strangers in the city: Reconfigurations of space, power and the social networks with Chinas floating population. Stanford CA.: Stanford University Press.

Zhao, Y. (2003). The role of migrant networks in labor migration: The case of China. Contemporary Economic Policy, 21(4), 500-511.

Zhu, C.J., \& Nyland, C. (2004). Marketization and social protection reform: emerging HRM issues in China. International Journal of Human Resource Management, 15(5), 853877. 
Table 1: Guanxi-Based Social Capital

\begin{tabular}{|c|c|}
\hline Forms of Social Capital & Guanxi Concepts \\
\hline Cognitive Dimension & $\begin{array}{l}\text { - Tong-xiang (people from the same birthplace) } \\
\text { - Tong-xue (people from the same educational institution) } \\
\text { - } \quad \text { Tong-shi (people from the same workplace) }\end{array}$ \\
\hline Relational Dimension & $\begin{array}{ll}\text { - } & \text { Renqing (a debt to an acquaintance) } \\
\text { - } & \text { Mianzi (face) } \\
\text { - } & \text { Huibao (a reciprocal favour) } \\
\text { Xinyong (trustworthiness) }\end{array}$ \\
\hline
\end{tabular}


Table 2: Data Structure

\begin{tabular}{|c|c|c|c|c|c|c|c|c|c|c|c|c|c|c|c|c|}
\hline \multirow{2}{*}{$\begin{array}{c}\text { Aggregate } \\
\text { Theoretical } \\
\text { Dimensions }\end{array}$} & \multirow[b]{2}{*}{ Themes } & \multicolumn{15}{|c|}{ Firms (Die-Casting Factories) } \\
\hline & & 1 & 2 & 3 & 4 & 5 & 6 & 7 & 8 & 9 & 10 & 11 & 12 & 13 & 14 & 15 \\
\hline \multirow{4}{*}{ Convenience } & Accessing a pool of potential candidates for a job through guanxi network (S) & $\sqrt{ }$ & & $\sqrt{ }$ & $\sqrt{ }$ & & $\sqrt{ }$ & $\sqrt{ }$ & & $\sqrt{ }$ & $\sqrt{ }$ & & $\sqrt{ }$ & $\sqrt{ }$ & $\sqrt{ }$ & $\sqrt{ }$ \\
\hline & Capturing and delivering information from a guanxi network concerning suitable jobseekers (S) & $\sqrt{ }$ & $\sqrt{ }$ & $\sqrt{ }$ & $\sqrt{ }$ & $\sqrt{ }$ & & $\sqrt{ }$ & $\sqrt{ }$ & $\sqrt{ }$ & & $\sqrt{ }$ & $\sqrt{ }$ & & $\sqrt{ }$ & $\sqrt{ }$ \\
\hline & $\begin{array}{l}\text { Individuals, who entrepreneurs and senior managers approved their qualifications for jobs, } \\
\text { recommend jobseekers with similar education and training backgrounds }(C)\end{array}$ & $\sqrt{ }$ & & $\sqrt{ }$ & $\sqrt{ }$ & $\sqrt{ }$ & & $\sqrt{ }$ & $\sqrt{ }$ & & $\sqrt{ }$ & $\sqrt{ }$ & $\sqrt{ }$ & $\sqrt{ }$ & $\sqrt{ }$ & $\sqrt{ }$ \\
\hline & $\begin{array}{l}\text { Having confidence in jobseekers who are recommend by members from guanxi networks that } \\
\text { entrepreneur and senior managers trusted }(\mathrm{R})\end{array}$ & & $\sqrt{ }$ & $\sqrt{ }$ & $\sqrt{ }$ & $\sqrt{ }$ & $\sqrt{ }$ & $\sqrt{ }$ & $\sqrt{ }$ & $\sqrt{ }$ & $\sqrt{ }$ & & $\sqrt{ }$ & $\sqrt{ }$ & $\sqrt{ }$ & \\
\hline \multirow{4}{*}{$\begin{array}{c}\text { Firms' } \\
\text { Attractiveness }\end{array}$} & $\begin{array}{l}\text { Encouraging members of firms' guanxi networks to spread favourable information about the firm } \\
\text { to other guanxi networks whose members have little knowledge about the firm (S) }\end{array}$ & $\sqrt{ }$ & $\sqrt{ }$ & & $\sqrt{ }$ & $\sqrt{ }$ & & $\sqrt{ }$ & & $\sqrt{ }$ & $\sqrt{ }$ & $\sqrt{ }$ & $\sqrt{ }$ & $\sqrt{ }$ & $\sqrt{ }$ & $\sqrt{ }$ \\
\hline & $\begin{array}{l}\text { Hiring employees who have similar backgrounds to enhance awareness of firms in their guanxi } \\
\text { networks (C) }\end{array}$ & & & $\sqrt{ }$ & & $\sqrt{ }$ & $\sqrt{ }$ & $\sqrt{ }$ & $\sqrt{ }$ & $\sqrt{ }$ & $\sqrt{ }$ & & $\sqrt{ }$ & & $\sqrt{ }$ & $\sqrt{ }$ \\
\hline & Hiring jobseekers that others in the same guanxi network respect $(\mathrm{C})$ & $\sqrt{ }$ & $\sqrt{ }$ & & $\sqrt{ }$ & & $\sqrt{1}$ & $\sqrt{ }$ & $\sqrt{1}$ & $\sqrt{1}$ & $\sqrt{ }$ & $\sqrt{ }$ & & $\sqrt{ }$ & $\sqrt{ }$ & $\sqrt{ }$ \\
\hline & Enhancing expectations about what they can get from a firm through building guanxi (R) & $\sqrt{ }$ & $\sqrt{ }$ & & & & $\sqrt{ }$ & & $\sqrt{ }$ & $\sqrt{ }$ & & $\sqrt{ }$ & $\sqrt{ }$ & $\sqrt{ }$ & & $\sqrt{ }$ \\
\hline \multirow{3}{*}{$\begin{array}{l}\text { Person- } \\
\text { Organization Fit }\end{array}$} & Acquiring detailed information about potential candidates for jobs though guanxi network (S) & $\sqrt{ }$ & & $\sqrt{ }$ & $\sqrt{ }$ & $\sqrt{ }$ & $\sqrt{ }$ & & $\sqrt{ }$ & $\sqrt{1}$ & $\sqrt{ }$ & $\sqrt{ }$ & & $\sqrt{ }$ & $\sqrt{ }$ & $\sqrt{ }$ \\
\hline & $\begin{array}{l}\text { Using members who share common backgrounds and histories in a guanxi network to help firms } \\
\text { screen suitable employees }(\mathrm{C})\end{array}$ & $\sqrt{ }$ & & & $\sqrt{ }$ & $\sqrt{ }$ & $\sqrt{ }$ & $\sqrt{ }$ & & $\sqrt{ }$ & $\sqrt{ }$ & $\sqrt{ }$ & & $\sqrt{ }$ & & $\sqrt{ }$ \\
\hline & $\begin{array}{l}\text { Building close, attached guanxi relationships with individuals who can provide information about } \\
\text { suitable candidates for a job and the firm through mutual reinforcement of favours }(\mathrm{R})\end{array}$ & $\sqrt{ }$ & $\sqrt{ }$ & & $\sqrt{ }$ & & $\sqrt{ }$ & & $\sqrt{ }$ & & & $\sqrt{ }$ & $\sqrt{ }$ & $\sqrt{ }$ & $\sqrt{ }$ & $\sqrt{ }$ \\
\hline
\end{tabular}

$\mathrm{S}=$ Structure Dimension of Guanxi-Based Social Capital; C = Cognitive Dimension of Guanxi-Based Social Capital; R = Relational Dimension of Guanxi-Based Social Capital

$\checkmark=$ at least one interviewee from this firm expressed this point. 


\section{Appendix 1: Case and Interviewees}

\begin{tabular}{|c|c|c|c|c|c|c|}
\hline \multirow[b]{2}{*}{ Factory } & \multirow[b]{2}{*}{ Type of Factory } & \multirow[b]{2}{*}{ Location } & \multirow{2}{*}{$\begin{array}{l}\text { Recruiting via } \\
\text { Network (\%) }\end{array}$} & \multicolumn{3}{|c|}{ Number of People Interviewed } \\
\hline & & & & Entrepreneur & Senior Managers & Factory Workers \\
\hline 1 & Die-casting Molding/Tooling & Huizhou & 85 & 1 & 2 & 2 \\
\hline 2 & Die-casting Molding/Tooling & Guangzhou & 90 & 1 & 1 & 2 \\
\hline 3 & Die-casting Molding/Tooling & Foshan & 68 & 1 & 3 & 3 \\
\hline 4 & Die-casting Part Machinery & Foshan & 56 & 1 & 3 & 5 \\
\hline 5 & Die-casting Part Machinery & Guangzhou & 76 & 1 & 2 & 3 \\
\hline 6 & Die-casting Part Machinery & Huizhou & 70 & 1 & 2 & 2 \\
\hline 7 & Die-casting Part Machinery & Dongguan & 67 & 1 & 2 & 4 \\
\hline 8 & Die-casting Part Machinery & Foshan & 61 & 1 & 3 & 3 \\
\hline 9 & Die-casting Part Subcontractor & Shenzhen & 71 & 1 & 1 & 2 \\
\hline $\mathbf{1 0}$ & Die-casting Part Subcontractor & Foshan & 52 & 1 & 2 & 6 \\
\hline 11 & Die-casting Part Subcontractor & Dongguan & 50 & 1 & 3 & 6 \\
\hline 12 & Die-casting Part Subcontractor & Dongguan & 48 & 1 & 4 & 7 \\
\hline 13 & Surface Treatment & Foshan & 78 & 1 & 1 & 2 \\
\hline 14 & Surface Treatment & Jiangmen & 80 & 1 & 1 & 1 \\
\hline 15 & Surface Treatment & Dongguan & 62 & 1 & 1 & 2 \\
\hline
\end{tabular}

Note: Average annual turnover $=¥ 103,140,000$ Renminbi; Average employee numbers $=447$ (According to the National Bureau of Statistics of China, small- and medium-sized firms have annual revenue less than $¥ 300,000,000$ and employ fewer than 2000 ). 